\title{
Kritik Ideologi terhadap Nilai Sosial Budaya Pernikahan dalam Novel Di Bawah Bayang-Bayang Ode Karya Sumiman Udu
}

\author{
Suriadin $\mathbf{P}^{1}$ ) \\ Universitas Indrprasta PGRI \\ Jalan Nangka No. 58 C/TB. Simatupang, Tanjung Barat, Jakarta Selatan 12530 \\ Apsanti Djokosuyatno ${ }^{2)}$ \\ Universitas Indrprasta PGRI \\ Jalan Nangka No. 58 C/TB. Simatupang, Tanjung Barat, Jakarta Selatan 12530 \\ Suriadinp88@gmail.com ${ }^{1)}$
}

\begin{abstract}
This study aims to gain an in-depth understanding of the intrinsic elements contained, to gain an in-depth understanding of the extrinsic elements, to gain an in-depth understanding of the social and cultural values of marriage, and to gain an in-depth understanding of the ideological critique of the socio-cultural values of marriage in Sumiman Udu's novel Di Bawah Bayang-Bayang Ode. The method used in this research is qualitative research using a genetic structuralism approach. The ideological criticism in the novel Di Bawah Bayang-Ode is a rejection of the belief of the Ode clan community that requires marriage to other clans so that parents are forced to marry their children to other clans. This is not only a form of discrimination against social classes that do not have an Ode clan, but also does not reflect the morals of an Ode clan. Besides that, the existence of the title "Ode" in the Butonese people is still very much appreciated, so that the marriage is done forcibly. Problems that occur next, when living the behavior of the household. Feelings of dislike (hate) are still lingering in the minds of the family, on the basis that they are not only entitled "Ode".
\end{abstract}

Keyword: Ideological Criticism, Socio-Cultural Values of Marriage, Under the Shadow of Ode

\begin{abstract}
Abstrak
Penelitian ini bertujuan untuk memperoleh pemahaman mendalam tentang unsur intrinsik, untuk memperoleh pemahaman mendalam tentang unsur ekstrinsik, untuk memperoleh pemahaman mendalam tentang nilai sosia budaya pernikahan, dan untuk memperoleh pemahaman mendalam tentang kritik ideology terhadap nilai sosial budaya pernikahan yang terdapat dalam novel $D i$ Bawah Bayang-Bayang Ode Karya Sumiman Udu. Adapun metode yang digunakan dalam penelitian ini adalah penelitian kualitatif dengan menggunakan pendekatan strukturalisme genetik. Kritik ideologi dalam novel Di Bawah Bayang-Bayang Ode merupakan penolakan atas keyakinan masyarakat bermarga Ode yang mengharuskan untuk menikah dengan sesama marga sehingga terjadi pemaksaan oleh orang tua untuk menikahkan anaknya dengan sesama marga. Hal ini tidak hanya sebagai bentuk diskriminasi terhadap kelas sosial yang tidak memiliki marga Ode, tetapi juga tidak mencerminkan akhlak seorang marga Ode. selain itu, keberadaan gelar "Ode" pada orang Buton masih sangat dihargai, sehingga pernikahan dilakukan secara terpaksa. Masalah yang terjadi selanjutnya, ketika menjalani laku kehidupan rumah tangga. Perasaan tidak suka (benci) masih melekat di pikiran keluarga, dengan dasar hanya tidak bergelar "Ode".
\end{abstract}

Kata kunci: Kritik Ideologi, Nilai Sosial Budaya Pernikahan, Dibawah Bayang-Bayang Ode

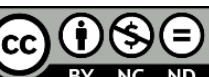

Creative Commons Attribution-NonCommercial-NoDerivatives 4.0 International License 


\section{PENDAHULUAN}

Novel merupakan salah satu karya sastra yang didalamnya terkandung cerita yang diungkapkan oleh pengarang dengan mengembangkan kisah yang terjadi dalam masyarakat. Semi (2012:32) berpendapat bahwa novel adalah karya yang mengungkapkan aspek-aspek kemanusiaan yang lebih mendalam dan disajikan dengan halus. Novel adalah bentuk karya sastra yang memiliki karakteristik tersendiri.

Salah satu unsur terpenting dari sebuah novel adalah tokoh. Seorang tokoh memiliki sifat-sifat dan karakter tertentu sebagai individu, baik dengan kepribadian baik atau pun buruk. Sifat dan karakter tokoh dapat dilihat melalui cara berbicara atau perilaku yang ditunjukkan dalam novel tersebut. Tokoh memegang peranan penting dalam membangun cerita. Penafsiran terhadap sikap dan watak seseorang sangat mendasar pada apa yang diucapkan dan apa yang dilakukan. Dengan kata lain, ucapan dan tindakan seseorang mencerminkan perwatakannya (Nurgiyantoro, 2015:173).

Novel Di Bawah Bayang-Bayang Ode adalah novel yang dipilih dalam penelitian ini karena sangat menarik untuk dikaji, pasalnya novel ini merupakan salah satu karya fiksi yang sudah beredar luas di masyarakat kabupaten wakatobi dengan sifatnya yang kontroversi dikarenakan novel ini bernuansa kedaerahan yang menceritakan kisah percintaan sepasang kekasih yang kandas ditengah jalan dikarenakan terhalang suatu ideologi atau nilai yang dianut oleh masyarakat setempat.

Novel ini mengisahkan tentang dua anak manusia yaitu Imam dan Amalia Ode, yang terpaksa merelakan cinta mereka demi adat yang dijunjung tinggi oleh keluarga dan masyarakatnya. Gelar 'ode' yang melekat pada nama Amalia membuatnya tidak berdaya untuk menentang keinginan ibu dan keluarga besarnya. Sebagai seorang yang bergelar 'ode', Amalia dipaksa menikah dengan sepupunya yang kaya raya agar anak keturunannya nanti juga mendapatkan gelar 'ode' dan mendapatkan jaminan kesejahteraan.Amalia tak kuasa menolak keinginan keluarga setelah ibunya sujud dihadapannya dan usaha melarikan diri untuk menemui kekasihnya Imam berhasil digagalkan oleh keluarga calon suaminya yang mempunyai pengaruh yang sangat besar di kampungnya.

Amalia akhirnya pasrah pada nasib terlebih setelah menyadari dirinya bahwa ia sedang menunggu Anastasia yang pernah ditemuinya di dalam mimpi. Imam yang mengetahui pernikahan Amalia dengan sepupunya tidak mungkin dihalangi karena dia bukanlah seorang yang bergelar 'ode' juga pasrah menerima nasib.

Imam sangat menyadari prinsip keluarganya bahwa gelar 'ode' bukanlah sesuatu yang diwariskan begitu saja melainkan anugrah atas buah perjuangan yang dilakukan untuk kepentingan negara sebagaimana kakeknya dahulu mendapatkan gelar tersebut. Imam akhirnya memantapkan diri untuk melanjutkan studinya hingga meraih gelar doktor dan mengabdi di Universitas Halu Oleo.

Novel ini tidak hanya bercerita tentang penderitaan manusia karena cinta terlarang, tetapi penderitaan masyarakatnya karena belum terbebas dari adat istiadat yang membelenggu pemikiran mereka untuk mendapatkan pendidikan dan 
kehidupan yang lebih layak. Seperti yang diungkapkan peneliti di awal tadi, bahwa karya sastra khususnya novel diciptakan oleh pengarang bukan sematamata untuk memberikan hiburan kepada pembacanya saja tetapi sekaligus berusaha menyampaikan nilai-nilai kehidupan sosial masyarakat yang bermanfaat bagi pembaca karya sastra tersebut, salah satunya adalah novel Dibawah Bayangbayang Ode, Novel ini hadir ditengah-tengah masyarakat pembaca Kabupaten Wakatobi bukan saja hadir sebagai bahan bacaan biasa atau hiburan semata akan tetapi diharapkan dapat memberikan pengaruh positif bagi pembacanya dalam kehidupannya wabil khusus dalam memahami hakekat gelar kebangsawanan Ode.

Dari latar belakang di atas peneliti tertarik untuk melakukan penelitian dengan menganalisis atau deskripsi konten pada novel Di bawah Bayang-Bayang Ode dengan menggunakan Teori Lucien Goleman yaitu Strukturalisme genetic. menurut Goldman.

\section{METODE}

Metode merupakan tindakan yang teratur yang digunakan untuk melaksanakan sesuatu pekerjaan agar tercapai apa yang di kehendaki. (Ali, 2011:168) menyatakan bahwa metode merupakan aspek aksiologi dari suatu paradigma yang merupakan aspek nyata dalam melakukan penelitian. Maksud dari pernyataan tersebut berkaitan dengan jenis penelitian, dalam artian tentang proses analisis data ataupun penyajiannya. Jadi, metode menyangkut masalah kerja untuk dapat memahami objek yang menjadi tujuan penelitian.

Adapun pendekatan yang digunakan oleh peneliti dalam penelitian ini yaitu dengan menggunakan mendekatan strukturalisme genetik. Strukturalisme genetik merupakan salah satu metode penelitian sastra yang populer digunakan dalam menganalisis karya sastra baik novel, cerpen, maupun puisi. Teori ini merupakan salah satu cabang sosiologi sastra yang memadukan antara struktur teks, konteks sosial, dan pandangan dunia pengarang (Yasa, 2012:28). Teori ini menekankan hubungan antara karya sastra dengan lingkungan sosialnya. Dalam masyarakat sesungguhnya manusia berhadapan dengan norma dan nilai, dalam karya sastra juga dicerminkan norma dan nilai yang secara sadar difokuskan dan diusahakan untuk dilaksanakan dalam masyarakat. Sastra juga melukiskan kecemasan, harapan dan aspirasi manusia. Oleh karena itu, kemungkinan karya sastra tersebut dapat dijadikan ukuran sosiologis yang paling efektif untuk mengukur tanggapan manusia terhadap kekuatan sosial.

Dalam menganalisis karya sastra ada dua kelompok karya sastra menurut Goldman (Damono, 1979:5), yaitu karya sastra yang dihasilkan oleh pengarang utama dan karya sastra yang dihasilkan oleh pengarang kelas dua. Karya sastra yang dihasilkan oleh pengarang utama adalah karya sastra yang strukturnya sebangun dengan struktur kelompok atau kelas sosial tersebut, sedangkan karya sastra yang dihasilkan oleh pengarang kelas kedua adalah karya sastra yang isinya sekedar reproduksi segi permukaan realitas sosial dan kesadaran kolektif. Dalam penelitian sastra yang menggunakan pendekatan strukturalisme genetik, menurut Goldman, karya sastra yang dianalisis disarankan menggunakan karya sastra 
ciptaan pengarang utama yang terdapat tokoh problematik atau mempunyai wira yang bermasalah yang berhadapan dengan kondisi sosial yang memburuk dan berusaha mendapatkan nilai-nilai yang sahih.

Sesuai panduan Goldman, karya sastra (novel) yang akan dianalisis adalah sastra yang masih menjadi salah satu titik perhatian masyarakat pembaca sastra, Olehnya itu penulis ingin meneliti novel 'Di Bawah Bayang-Bayang Ode Karya Sumiman Udu', dimana novel ini menarik dan masih layak untuk dibahas karena di novel ini ada nilai yang saling bertentangan yakni nilai agama dan nilai budaya. Novel ini syarat akan kenflik batin dan konflik keluarga, dimana tokoh pertama dan kedua tidak disatukan cintanya karena dihadapkan pada status sosial dari keduanya yang berbeda yaitu kepemilikan gelar "ode".

\section{HASIL DAN PEMBAHASAN}

\section{Hasil}

Alur yang terdapat dalam novel dengan judul Di Bawah Bayang-Bayang Ode ini terdiri atas: (1) Pengantar atau prolog dari halaman pertama hingga ke tuju. (2) Terdiri dari sebelas Bab dari halaman delapan hingga halaman dua ratus empat puluh empat. (3) Epilog dari halaman seratus dua puluh satu hingga dua ratus empat puluh empat. Secara keseluruhan novel ini menggunakan cerita alur campuran.

Adapun tema yang terdapat dalam novel Di Bawah Bayang-Bayang Ode yaitu menceritakan kisa perjuangan cinta sepasang kekasih yang merelakan cinta mereka yang tidak direstui dikarenakan perbedaan kasta atau status sosila dari keduangya berbeda. Novel Di Bawah Bayang-Bayang Ode mengamanatkan (1) Jika ingin maju, maka lupakannlah masa lalu dan fokuslah pada masa depan. (2) Mendapatkan kemerdekaan dan kebebasan dalam berfikir dan menentukan nasipnya sendiri.(3) Jangan terbelenggu oleh ketakutan, dan beranilah untuk berkata jujur. (4) Bakti seorang anak yang melaksanakan perintah ibu dan keluarga besanya.(5) Hanya seorang pecundanglah yang tidak beranikan diri untuk menjalani kenyataan hidup dan tidak berani mengambil keputusan. (6)Mehami makna atau hakikat pemberian gelar ode. Gelar ode tidak diwariskan berdasarkan garis keturunan melainkan diberikan kepada mereka yang memliki andil atau jasa pada kesultanan.

Nilai Sosial Budaya Pernikahan dalam Novel Di Bawah Bayang-Bayang Ode yaitu berkaitan dengan adat istiadat serta syarat seorang pria dan wanita itu menikah antara lain:(1) Pernikahan Harus Melalui Proses Pelamaran Atau Pertunangan. (2)Pernikahan Harus Direstui Oleh Orang Tua. (3)Pernikahan Harus Melalui Proses Upacara/Ritual (Akad nikah). (4)Pernikahan Harus Dilakukan Sesama Marga. (5)Diwajibkan Laki-Laki Dan Perempuan Untuk Menikah.

\section{Pembahasan}

Kritik Ideologi terhadap Nilai Sosial Budaya Pernikahan dalam novel $D i$ Bawah Bayang-Bayang Ode Karya Sumiman Udu merupakan kepercayaan atau 
keyakinan yang dianut oleh masyarakat khususnya masyarakat yang bermarga Ode yaitu keharusan untuk menikah dengan sesama marga. Marga Ode memiliki kelas sosial yang paling tinggi dibandingkan dengan marga Wa Ode dan masyarakat biasa bagi masyarakat Buton. Oleh karena itu, pernikahan sesama marga Ode dilakukan dalam upaya untuk menjaga dan mempertahankan status sosial kemargaan Ode.

Keharusan menikah dengan sesama marga Ode inilah yang mendorong terjadinya pemaksaan oleh orang tua untuk menikahkan anaknya dengan sesama marga Ode. Hal inilah yang dikritik oleh penulis melalui novel Di Bawah BayangBayang Ode Karya Sumiman Udu".

Novel "Di Bawah Bayang-bayang Ode" mengisahkan percintaan seorang lelaki yang mencintai perempuan yang bergelar "Ode" yakni Amalia Ode. Sebagian masyarakat Buton masih menganggap bahwa "Ode" merupakan gelar bangsawan yang diturunkan dari darah biru. Oleh karena itu, mereka masih menganggap bahwa masyarakat Buton terdiri atas kelas bangsawan (bergelar Ode) dan masyarakat biasa yang tidak memiliki gelar "Ode".

Orang bangsawan (Ode) digambarkan sebagai orang yang kaya, pandai dan berahlak, sehingga dalam perjodohanpun bahwa seorang yang tidak bergelar "Ode" tidak pantas menikah dengan seorang yang bergelar "Ode". Oleh karena itu, diharuskan yang bergelar ode menikah dengan yang bergelar ode juga. Pemikiran seperti itulah yang ditolak atau dilawan oleh tokoh utama dalam novel karena dianggap sebagai bentuk diskriminasi dan sudah tidak relevan lagi untuk diyakini atau diikuti. Seperti yang terdapat dalam kutipan wawancara berikut ini:

"Kita mau katakana ini sebagai bentuk diskriminasi, bisa saja kita katakan ya! Karena secara tidak langsung mendisriminasi kelas sosial yang lain.” (Udu, 2015)

Kisah percintaan berbeda kasta (kelas sosial) antara tokoh Imam dengan Amalia Ode merupakan kisah cinta penuh rintangan adat, budaya, dan sejarah Buton kususnya di Kabupaten Wakatobi. Bagi sebagian masyarakat Boton, gelar "Ode" merupakan gelar nama dari keturunan Ode yang harus dipertahankan karena "Ode" diyakini sebagai orang yang memiliki kelas atas (bangsawan). Jika dilihat dari sejarahnya, gelar ode merupakan gelar yang diberikan oleh kaum kerajaan/ bangsawan, seperti dalam kutipan berikut:

"Gelar ode ana pertama kali ogunakan ako'e pada abad ke-13 atau ke-14 te raja pertamamo ubuton ana, Ratu Wa Kaakaa. Kata ode ana oberasal mini prama sastra melayu yang te ma'anano pujaan kua mia moto jasa i kerajaan atau kesultanan...."

"Imolengomo ai, raja atau sultan buton itu, ketika olantik'e yakamo opake'e na gelaratu. Makannya hampir rata-rata tenga'ano mbea ala'a kata ode. Karena ojagamo bai te kemurnian u ode iso bai". (Udu, 2015)

Adapun bentuk kritikan ideologi pernikahan yang ditunjukan oleh Amalia Ode (Lia) dan Imam dalam novel "Di Bawah Bayang-Bayang Ode" adalah penolakan mereka terhadap keputusan orang tua Amalia Ode yang mengharuskan Amalia untuk menikah dengan sesama marga Ode, seperti pada kutipan berikut ini: 
"Dengarkanlah ibu, kalau kau tetap keras kepala, namamu akan rusak. Nama keluarga juga rusak. Kau akan jadi buah bibir orang-orang kampung. Mereka akan bila kau tak tau diri, melanggar adat. Kau tak takut terkena bala, kau akan disisihkan masyarakat. Kau adalah orang yang tak bergelar ode....”

Bagi Amalia Ode dan Imam, gelar Ode sudah tidak penting bagi mereka, sekalipun pada akhirnya keduanya tidak mampu melawan kehendak orang tua, sehingga Amalia Ode tetap menikah dengan laki-laki yang bergelar Ode. Padahal berdasarkan hasil wawancara dengan tokoh adat Buton yang bergelar Ode bahwa sekalipun dalam aturan adat diharuskan marga yang bergelar ode untuk menikah dengan sesama marga Ode, akan tetapi dalam urusan pernikahan atau perjodohan tidak boleh ada paksaan, seperti dalam kutipan berikut ini:

"Kalau kita mengambil aturan adat memang laki-laki ataupun perempuan yang bergelar ode harus menikah dengan orang yang bergelar ode juga, sehingga gelar itu dapat tetap terjaga keberlangsungannya ke anak cucunya, sebab kaboka (mahar) yang bergelar Ode dan bukan bergelar ode itu berbeda..."

Berdasarkan data di atas, maka dapat disimpulkan bahwa kritik ideologi dalam novel Di Bawah Bayang-Bayang Ode merupakan penolakan atas keyakinan masyarakat bermarga Ode yang mengharuskan untuk menikah dengan sesama marga sehingga terjadi pemaksaan oleh orang tua untuk menikahkan anaknya dengan sesama marga. Hal ini tidak hanya sebagai bentuk diskriminasi terhadap kelas sosial yang tidak memiliki marga Ode, tetapi juga tidak mencerminkan akhlak seorang marga Ode.

\section{SIMPULAN}

Kritik ideologi dalam novel Di Bawah Bayang-Bayang Ode merupakan penolakan atas keyakinan masyarakat bermarga Ode yang mengharuskan untuk menikah dengan sesama marga sehingga terjadi pemaksaan oleh orang tua untuk menikahkan anaknya dengan sesama marga. Hal ini tidak hanya sebagai bentuk diskriminasi terhadap kelas sosial yang tidak memiliki marga Ode, tetapi juga tidak mencerminkan akhlak seorang marga Ode. selain itu, keberadaan gelar "Ode" pada orang Buton masih sangat dihargai, sehingga pernikahan dilakukan secara terpaksa. Masalah yang terjadi selanjutnya, ketika menjalani laku kehidupan rumah tangga. Perasaan tidak suka (benci) masih melekat di pikiran keluarga, dengan dasar hanya tidak bergelar "Ode".

\section{DAFTAR RUJUKAN}

Ali, M. (2011). Memahami riset perilaku dan sosial. Bandung: Pustaka Cendikia Utama

Damono, S. D. (1979). Sosiologi: Sebuah pengantar. Jakarta: Pusat Pembinaan dan Pengembangan Bahasa Departemen Pendidikan dan Kebudayaan. 
Diskursus: Jurnal Pendidikan Bahasa Indonesia

Vol. 4, No. 2, Agustus 2021, pp. 107-113

p-ISSN: 2615-4935

e-ISSN: 2615-4943

Nurgiyantoro, B. (2015). Teori pengkajian fiksi. Yogyakarta: Gajah Mada University Press.

Semi, M. A. (2012). Metode penelitian sastra. Bandung: Angkasa.

Udu, S. (2015). Di Bawah Bayang-Bayang Ode. Pekanbaru: Seligi Press.

Yasa, I. N. (2012). Teori sastra dan penerapannya. Bandung: Karya Putra Darwati. 